\title{
Disentangling factors controlling fruit and seed removal by rodents in temperate forests
}

\author{
Ramón Perea, Alfonso San Miguel and Luis Gil* \\ Departamento de Silvopascicultura, ETSI Montes, Universidad Politécnica de Madrid, Ciudad Universitaria s/n, \\ 28040 Madrid, Spain
}

\begin{abstract}
Fleshy fruits fall on to the ground together with cleaned seeds previously ingested by primary dispersers, offering a wide range of fruits and seeds to the ground foragers. Although nutritional properties strongly differ between fruits and seeds, this different seed presentation (cleaned seeds versus seeds within the pulp) has not been addressed in seed removal studies. This study reports on the removal of fruits versus their seeds in five fleshy-fruited species in a temperate forest. We found that rodents removed most of the seeds and partially consumed most of the fruits, preferring seeds to fruits. Rodents bit the fruits to extract the seeds, leaving most of the pulp. We found a preference ranking for the seeds (Sorbus aucuparia $>$ Ilex aquifolium > Sorbus aria > Rosa canina > Crataegus monogyna) but no preferences were found for the fruits, probably due to their similarities in pulp constituents. Seed and fruit choice were affected by chemical and physical properties and not by their size. The presence of alternative and preferred seeds (nuts) delayed the encounter of the fruits and seeds and diminished their removal rates. We found that higher rodent abundance is not necessarily associated with higher removal rates of fleshy fruits. Rodent abundance, fruit size and seed size are minor factors in the removal of fleshy fruits and their seeds. This study underlines that scatter-hoarding rodents are important removers of fleshy fruits and their seeds, producing a differential seed removal depending on the seed presentation (with or without pulp), the nutritional properties of the seeds (but not of the fruits) and the presence of alternative food.
\end{abstract}

Keywords: food availability, fruit/seed size, nut crop, nutritional properties, rodent abundance, scatterhoarding, seed choice

*Correspondence

Email: luis.gil@upm.es

\section{Introduction}

Seed dispersal and predation play a key role in seedling establishment (Vander Wall, 2001), spatial distribution (Schupp, 1988; Puerta-Piñero et al., 2010), and the demographic and genetic structure of plant populations (Vander Wall, 2001; Valbuena-Carabaña et al., 2005). Most dispersal studies usually consider seed properties rather than fruit properties because seeds are the structures containing the embryo, which eventually produces the new seedling. However, fleshy fruits contain seeds that remain inside the pulp even after falling on to the ground. Most largesized fruits in temperate ecosystems usually fall on to the ground and remain intact, with no dispersal from the trees (Herrera, 1984). Some other medium and small-sized fruits contain seeds that are mostly found on the ground after having been regurgitated or defecated by primary dispersers (Herrera, 1984; Obeso and Fernández-Calvo, 2002). Consequently, a wide range of fruits and seeds are found on the ground, even from the same plant species.

Birds and carnivores are considered the main foragers of fleshy fruits in temperate ecosystems (Herrera, 1984, 1989; Willson, 1993). However, the interaction between intact fleshy fruits and rodents has been poorly studied. Partitioning the effects of vertebrates is crucial since different guilds of animals are likely to differ in the temporal and spatial scales of their effects, their foraging ecology (predation versus dispersal), their functional responses and their species preferences (Hulme and Borelli, 1999). Studies that ignore these differences may misrepresent factors thought to be important in plant demography (Hulme, 1998). However, some of these different modes of dispersal/predation were found to be linked. Vander Wall et al. (2005) observed that rodents disperse seeds from fleshy-fruited species that were previously defecated by frugivorous birds. Unlike birds and carnivores, rodents with a caching behaviour lead to potential benefits in natural regeneration by moving the seeds away from unsuitable germination sites 
(e.g. rocks or ground surface) or by burying the seeds and reducing the exposure to strict seed predators, fungi or desiccation (Lambert, 2002). Besides, competition among seedlings is more likely to occur in faeces containing several seeds (Howe, 1989). Instead, rodents disperse seeds to more suitable sites for germination and establishment (Vander Wall et al., 2005).

Optimal foraging theory states that animals forage in a way to minimize predation risk and maximize their energy intake (Brown and Kotler, 2004; Fedriani and Manzaneda, 2005). Thus, nutritional properties of the food items play a crucial role in seed choice and foraging activity of seed-eating rodents (Wang and Chen, 2008). Nutritional properties may differ considerably between fruits and seeds among plant species (Kollmann et al., 1998), but also within the same species (Pulliainen, 1978). However, most dispersal studies have only addressed seed properties although they are located inside the fruits, which usually have different properties from the seeds. Those differences (in both physical and chemical properties) might cause a differential selection by foragers among fruits and seeds. Foragers may prefer fruits from some species and seeds from others, leading to different seed removal and dispersal. However, the presentation of the seeds (cleaned versus within ripe fruits) has not received attention, even though it may have important ecological and evolutionary implications for natural regeneration.

Highly nutritious seeds are more attractive to seed foragers, in agreement with the optimal foraging theory (Stephens and Krebs, 1986). Nuts such as acorns, beechnuts and hazelnuts are high-energy seeds and, therefore, are more likely to be eaten and stored (Vander Wall, 2003; Xiao et al., 2005). These highly nutritious seeds ripen and fall at the same time as many fleshy fruits of temperate ecosystems, mostly during autumn. Consequently, nuts and fleshy fruits coincide on the ground at the same time, offering a high variety of seeds and fruits to the foragers. However, very few studies have tackled the influence of preferred seeds (e.g. nuts) on the removal of nonpreferred seeds (fleshy fruits). Thus, the effects of alternative food on seed removal need to be explored.

Seed-foraging rodents remove a proportion of the available seeds and fruits, selecting the most nutritious items to maximize their energy intake (Kerley and Erasmus, 1991). In addition, higher seed densities or lower forager abundance favour satiation of seed foragers (Janzen, 1971) and, thus, more seeds will escape from removal. According to these premises, we pose several predictions in order to disentangle the factors controlling fruit and seed removal in fleshy fruits of temperate forests: (1) rodents would remove proportionally more seeds (higher energy content per volume) than intact fruits; (2) rodents would prefer fleshy-fruited species with large seeds and fruits over those species with small seeds and fruits; (3) rodents would prefer cleaned seeds (ready to eat) to seeds that are contained within the fleshy fruits; (4) rodents would remove a lower proportion of seeds and fruits of fleshy-fruited species in sites where alternative and more nutritious seeds (nuts) are abundant; (5) seed and fruit encounter under the same microhabitat would be more rapid in sites where seed production is lower or rodent density is higher.

\section{Materials and methods}

\section{Study area and sites}

The study area was located in the Ayllon mountain range in central Spain $\left(3^{\circ} 30^{\prime} \mathrm{W}, 41^{\circ} 07^{\prime} \mathrm{N}\right.$, Madrid province), at $1400 \mathrm{~m}$ above sea level, in a submediterranean climate with $958 \mathrm{~mm}$ annual rainfall and 2-month summer dry season. This study was conducted in a temperate mixed forest of Quercus pyrenaica, Quercus petraea, Fagus sylvatica and some woody, fleshy-fruited species (Sorbus aucuparia, Sorbus aria, Ilex aquifolium, Crataegus monogyna and Rosa sp.). These fleshy-fruited species produce a high fruit crop in autumn, coinciding with the acorn crop. The understorey is also made up of shrubby perennial species such as Genista florida, Adenocarpus hispanicus and Cytisus scoparius. Different habitats can be found according to vegetation composition and structure, resulting in a heterogeneous forest (Pardo et al., 2004). Thus, we distinguish three main study habitats (study sites) according to woody plant composition and fleshy fruit availability for foragers (Table 1). Distances between sites were, at least, $500 \mathrm{~m}$ to ensure statistical independence. The tree inventory for each site was performed in 2005 (García, 2006) (Table 1). Each site was selected in the tree inventory according to their homogeneity in tree composition and structure.

Three digital video cameras with night vision (Leaf River IR-5.5 MP) were used in three supply stations (one for each site) during 15-19 days in October 2009 to identify the animal species removing fleshy-fruits and their seeds. A total number of 131 videos were taken and only wood mice (Apodemus sylvaticus) and wild boar (Sus scrofa) were recorded removing or consuming fruits and seeds. Sixty-nine of the recordings were of wood mice and only one video was of wild boar. The rest of video recordings contained no animals. These results indicate that rodents are the main seed and fruit removers of fleshy-fruited species on the ground. Therefore, this study will focus on the removal caused by rodents. No active granivorous ants were found in late October and November, probably due to the low temperatures for that time of the year in the study area. 
Table 1. Summary of the study sites characteristics. Crop size and rodent density estimations were obtained for the year 2009

\begin{tabular}{|c|c|c|c|c|c|c|}
\hline \multirow[b]{2}{*}{ Study site } & \multirow[b]{2}{*}{ Species composition } & \multirow{2}{*}{$\begin{array}{l}\text { Tree density } \\
\text { (stems ha }^{-1} \text { ) }\end{array}$} & \multirow{2}{*}{$\begin{array}{c}\text { Basal area } \\
\left(\mathrm{m}^{2} \mathrm{ha}^{-1}\right)\end{array}$} & \multirow{2}{*}{$\begin{array}{c}\text { Crop size } \\
\text { (seeds } \mathrm{m}^{-2} \text { ) }\end{array}$} & \multicolumn{2}{|c|}{$\begin{array}{l}\text { Rodent density } \\
\text { (individuals ha }^{-1} \\
\text { mean } \pm \mathrm{SD} \text { ) }\end{array}$} \\
\hline & & & & & August & November \\
\hline 1. Low nut production & Quercus/Fagus & 74 & 2.35 & 2.92 & $11.1 \pm 2.9$ & $13.3 \pm 5.2$ \\
\hline High fleshy fruit production & Fleshy-fruited species & 404 & 2.40 & 104.63 & & \\
\hline 2. Low nut production & Quercus/Fagus & 640 & 19.54 & 25.46 & $15.6 \pm 9.1$ & $4.4 \pm 1.0$ \\
\hline Low fleshy fruit production & Fleshy-fruited species & 51 & 0.26 & 5.87 & & \\
\hline 3. High nut production & Quercus/Fagus & 679 & 25.82 & 67.77 & $22.8 \pm 8.7$ & $22.2 \pm 3.9$ \\
\hline Low fleshy fruit production & Fleshy-fruited species & 59 & 0.05 & 3.30 & & \\
\hline
\end{tabular}

\section{Fruit production}

To estimate the crop size we used $1-\mathrm{m}^{2}$ seed traps in two of the sites. Site 1 had 48 traps in a $6 \times 8$ rectangular grid and Site 3 had 61 traps in an approximate $12 \times 5$ rectangular grid plus an extra trap. Seed traps were located $7 \mathrm{~m}$ from each other inside the grid. In Site 2 we had a systematic sampling design in a $7 \times 5$ rectangular grid. We used a $1-\mathrm{m}^{2}$ wooden square placed on the ground every $7 \mathrm{~m}$. Traps were covered by a metallic mesh (openings of $1 \mathrm{~cm}$ ) to avoid seed and fruit removal by foragers. Seeds were collected from the traps and counted in October and November 2009. A random sample of 50 fruits and seeds of each fleshy-fruited species was weighed. Fruit production for each site is shown in Table 1.

\section{Small mammal trapping}

Live trapping of small mammals was conducted in each site on three consecutive days. Two trapping periods were established: August and November 2009. Trapping stations were located according to a rectangular $5 \times 4$ grid, with $15 \mathrm{~m}$ between stations. Each station had one trap, so that sampling effort was 120 trap-nights per site. Trap dimensions were $27 \times 7.5 \times 7.5 \mathrm{~cm}$ and they were baited with acorns and sunflower seeds. Captured individuals were identified to species, marked with numbered ear tags and then released at the point of capture.

\section{Seed removal experiment}

We built seven supply stations at each site. Stations were built with a wire mesh (square openings of $1.2 \mathrm{~cm})$ in a cubic shape $(50 \mathrm{~cm}$ length $\times 50 \mathrm{~cm}$ width $\times 3 \mathrm{~cm}$ height) to exclude removers other than small mammals. All stations were located under shrub cover (crown diameter over $2 \mathrm{~m}$ ) to standardize microhabitat. Stations were located on a transect, separated approximately $50 \mathrm{~m}$ from each other within each site. We placed a Petri dish (90-mm diameter) under the wire mesh of each station, containing 25 seeds and 25 fruits of the following fleshy-fruited species: Sorbus aucuparia, Sorbus aria, Ilex aquifolium, Crataegus monogyna and Rosa canina. Each Petri dish contained five seeds and five intact fruits of each species and one sunflower seed to confirm that rodents were in the station and did not take any fruits or seeds. Seeds were extracted manually from the pulp of the fruits. Plastic gloves were used when handling fruits and seeds to avoid contamination with human odour. The median number of seeds per fruit was highly variable for $R$. canina $(9.8 \pm 2.4)$, constant for C. monogyna (one seed) and of low variability for I. aquifolium ( $3.1 \pm 0.7$ seeds per fruit) and both Sorbus species ( $3.8 \pm 0.4$ for S. aria and $4.4 \pm 0.7$ for S. aucuparia; $N=20$ for each species). Fruits were collected from the study area in October 2009 and a total number of 1050 fruits and seeds (3 sites $\times 7$ stations $\times 50$ fruits/seeds) were offered to the rodents.

The experiment started at the end of October 2009 and lasted 30 days. We checked the stations every day during the first $14 \mathrm{~d}$ after fruit/seed offer and, then, every other day until day 30 . We used this period (end of October and November) because all studied species were in the drop period. We noted all fruits and seeds that were removed, partially eaten and/or consumed in situ.

\section{Data analysis}

Small mammal density was estimated for each site and period according to the capture-mark-recapture Schnabel method (Krebs, 1999). To analyse seed and fruit removal we performed several Mixed Models according to different objectives. All models were performed using the R 2.12.2 free software (http:// www.r-project.org/). First, we used a Generalized Linear Mixed Model (GLMM) to analyse seed and fruit fate using the 'lmer' function. We took a binary response variable (whether the seed or fruit was 


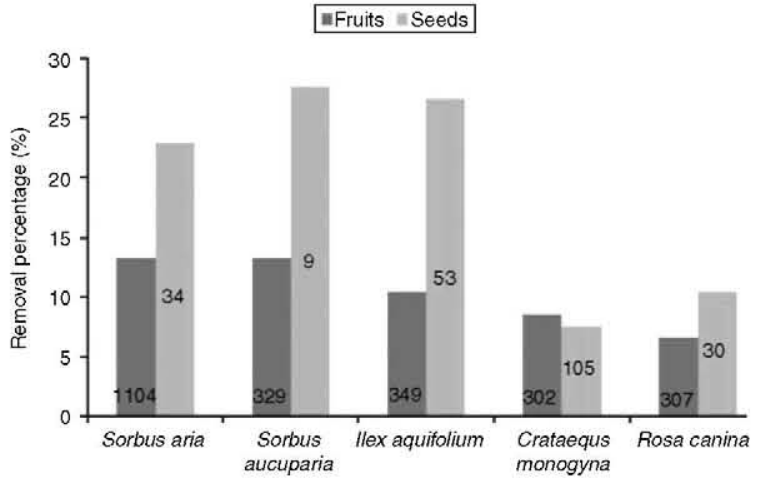

Figure 1. Seed and fruit selection by rodents given as the percentage of removal on the first day that rodents encounter the stations (when all seeds and fruits were available). Values inside the bars indicate fruit and seed mass (in $\mathrm{mg}$ ) to show that preferences for fruits and seeds are not related to the mass.

removed - value 1 - or intact -value 0). Fruits and seeds that were consumed in situ were included as removed (value 1). Fixed effects were seed presentation (cleaned seeds versus seeds within the pulp), site and plant species. Interactions among these three factors were also considered. The binary response variable was taken for different times throughout the experiment to assess possible differences in the main effects and their interactions along time. Consequently, we took the binary response variable for the first day rodents encountered the stations (when all seeds/ fruits were available), for day 5 (medium-term, when $50 \%$ of the fruits / seeds were removed) and for the last day of the experiment (day 30). Random effects were those considered in the nested structure (supply station nested within site).To analyse whether fruits were opened to extract the seeds we did a GLMM with a data subset (seed presentation $=$ fruit). The response variable was fruit opened or not (binary) and the fixed factors were plant species and site. Opened fruits were those slightly eaten to reach the seeds. Finally, to analyse whether time to encounter the seeds varied among sites, we used survival analysis for constant hazard and no censoring since all supply stations were finally discovered by rodents. A Generalized Linear Model (GLM) with gamma error was used following Crawley (2007). We tested for overdispersion in all GLMM and GLM models.

\section{Results}

Rodents showed a clear preference for cleaned seeds over intact fruits containing the seeds (Fig. 1, Table 2). Rodents removed most of the seeds whereas most of the fruits either remained intact or were partially consumed (Fig. 2a). Interestingly, rodents were found to bite the fruits (partial consumption) to extract the seeds instead of removing or consuming the whole fruits (Fig. 2a). Factors with significant effects on the removal of seeds not only include seed presentation, but also plant species and site location (Table 2). Thus, rodents showed an evident preference for cleaned seeds of some plant species whereas no clear preference for intact fruits of any species was found (Table 3). Moreover, large fruits or seeds were not preferred over small ones (Fig. 1). The site with the lowest seed production showed the most rapid seed encounter (Table 4). Sites also interacted with species and seed presentation, which reveals that differences in sites significantly affect the removal and selection of fruits and seeds. However, differences among sites were decreasing throughout the experiment due to the increasing encounter of supply stations and the continuous removal of the remaining seeds along time (Table 2).

\section{Initial fate and species selection}

For the first day that rodents encountered the stations, $3.1 \%(N=16)$ of the fruits and $18.3 \%(N=96)$ of the

Table 2. Summary of the models used to analyse the factors affecting removal for the initial fate (the first day rodents encountered the stations), medium-term fate (50\% of the fruits/seeds were removed) and final fate (end of experiment). Interactions between factors are represented by asterisks

\begin{tabular}{|c|c|c|c|c|c|c|c|c|c|}
\hline \multirow[b]{2}{*}{ Fixed effects } & \multicolumn{3}{|c|}{$\begin{array}{l}\text { M1. Initial } \\
\text { fate (day } 1)\end{array}$} & \multicolumn{3}{|c|}{$\begin{array}{l}\text { M2. Medium term } \\
\text { fate (day 5) }\end{array}$} & \multicolumn{3}{|c|}{$\begin{array}{c}\text { M3. Final } \\
\text { fate (day 30) }\end{array}$} \\
\hline & $\mathrm{df}$ & $x^{2}$ & $P$ value & $\mathrm{df}$ & $x^{2}$ & $P$ value & $\mathrm{df}$ & $\chi^{2}$ & $P$ value \\
\hline Seed presentation (seeds vs. fruits) & 1 & 8.85 & 0.003 & 1 & 16.63 & $<0.001$ & 1 & 34.72 & $<0.001$ \\
\hline Plant species & 4 & 21.78 & $<0.001$ & 4 & 39.05 & $<0.001$ & 4 & 66.30 & $<0.001$ \\
\hline Site & 2 & 12.84 & 0.002 & 2 & 14.51 & $<0.001$ & 2 & 2.86 & 0.249 \\
\hline${ }^{*}$ Seed presentation $\times$ species & 4 & 8.95 & 0.062 & 4 & 10.08 & 0.039 & 4 & 31.83 & $<0.001$ \\
\hline$*$ Species $\times$ site & 8 & 24.91 & 0.002 & 8 & 6.76 & 0.563 & 8 & 13.83 & 0.086 \\
\hline$*$ Seed presentation $\times$ site & 2 & 3.85 & 0.146 & 2 & 29.48 & $<0.001$ & 2 & 23.49 & $<0.001$ \\
\hline
\end{tabular}

M1: Akaike information criterion $(\mathrm{AIC})=653.3 ;$ Deviance $=650.3 ;$ Dispersion $=0.71 . \mathrm{M} 2: \mathrm{AIC}=778.6$; Deviance $=730.6$; Dispersion $=0.75$. M3: $\mathrm{AIC}=871.3$; Deviance $=823.3$; Dispersion $=0.93$. Bold type indicates statistical significance $(P<0.05)$. 

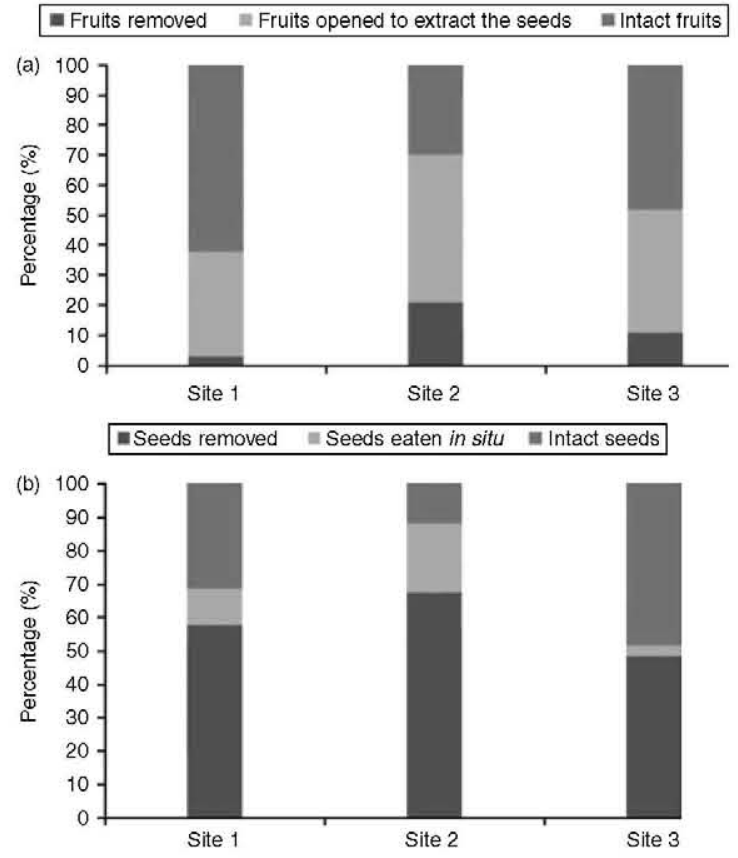

Figure 2. Fate of fruits (a) and seeds (b) at the end of the experiment (after $30 \mathrm{~d}$ of seed and fruit offer to the rodents) for different sites. Sites differed strongly in seed production: Site 1 = high fleshy fruit availability; Site 2 = low fleshy fruit availability; Site 3 = low fleshy fruit but high acorn availability.

seeds were removed. A higher proportion of fruits remained intact $(89.5 \% ; N=470)$ in comparison to seeds $(80.9 \% ; N=425)$. Moreover, $7.4 \%(N=39)$ of the fruits and $0.8 \%(N=4)$ of the seeds were partially eaten. No rodent preference for fruit species was found $(P>0.05$ between the most preferred and the least preferred species; Table 3). Cleaned seeds of both Sorbus species and I. aquifolium were preferred over Rosa and Crataegus (Fig. 1; Table 3). No significant differences were found between the selection of Rosa and Crataegus seeds $(Z=0.77 ; P=0.442)$ and among Ilex, S. aucuparia and S. aria (Table 3).

Time to encounter the stations was significantly shorter for Site 2, followed by Site 1 and Site 3, with significant differences (Table 4). In addition, Site 2 had higher significant removal rates compared to Site 1 and Site 3 (Fig. 2b, Table 4). However, sites 1 and 3 had no differences in removal rates (Table 4). Species and site was the only significant interaction between the main effects (Table 2) due to the fact that $S$. aria and Ilex fruits were preferred in Site 3 over the rest of species $(P<0.047$ for all cases) with no differences between Ilex and $S$. aria fruits $(Z=-0.006 ; P=0.995)$ and among Crataegus, Rosa and S. aucuparia ( $P>0.996$ for all cases).

\section{Medium-term and final fate}

Medium-term fate was obtained for day 5 , when more than $50 \%$ of the fruits and seeds were finally selected, either removed or consumed. Plant species resulted in a significant factor to determine seed and fruit removal for medium and final fate (Table 2). However, site affected medium-term fate (more seeds removed) but not the final fate (Table 2). At the end of the experiment (day 30), seeds were consumed in situ (shells found in the dish) in $11.6 \%(N=61)$, removed in $57.9 \%$ $(N=304)$ and intact in $30.5 \%(N=160)$. Fruits were partially consumed in $42.8 \%(N=225)$, removed in $10.5 \%(N=55)$ and intact in $46.7 \%(N=245)$.

Site was found to interact with seed presentation (Table 2), because more fruits remained intact in Site 2 in comparison to sites 1 and 3 (Fig. 2a). Significant interaction between species and seed presentation was also found (Table 2). This can be explained because Crataegus was the only species with fruits preferred over seeds. Fruits were opened to extract the seeds (seeds eaten/removed but some part of the fruit remained) in $78.2 \%$ of the non-intact fruits. Site 1 had the highest significant percentage of seed extraction compared to the lowest, found in Site 2 (Fig. 2a, Table 4).

\section{Discussion}

Rodents were important seed removers of all fleshy fruits, with only $31.5 \%$ of the seeds remaining intact.

Table 3. Summary of the preference ranking for the five fleshy-fruited species depending on seed presentation (intact fruits versus cleaned seeds). Numbers in the preference rank vary from the most preferred (1st) to the least (5th). $Z$ and $P$ values are given with regard to Sorbus aria

\begin{tabular}{|c|c|c|c|c|c|c|}
\hline & \multicolumn{3}{|c|}{ Fruits } & \multicolumn{3}{|c|}{ Seeds } \\
\hline & $\begin{array}{c}\text { Preference } \\
\text { rank }\end{array}$ & $Z$ value & $P$ value & $\begin{array}{c}\text { Preference } \\
\text { rank }\end{array}$ & $Z$ value & $P$ value \\
\hline Sorbus aria & 1 st & - & - & $3 r d$ & - & - \\
\hline Sorbus aucuparia & 2nd & $-2.4 \cdot 10^{-6}$ & 1.000 & $1 \mathrm{st}$ & 0.97 & 0.333 \\
\hline Ilex aquifolium & $3 r d$ & -0.73 & 0.466 & 2nd & 0.78 & 0.435 \\
\hline Crataegus monogyna & 4th & -1.24 & 0.215 & 5 th & -3.43 & $<0.001$ \\
\hline Rosa canina & 5 th & -1.77 & 0.077 & 4th & -2.77 & 0.005 \\
\hline
\end{tabular}

Bold type indicates statistical significance. 
Table 4. Summary of the influence of site on the time to encounter the stations, on initial removal rate and on seed extraction from the non-intact fruits. Sites strongly differed in seed production: $\mathrm{S} 1=$ high fleshy fruit production; S2 = low fleshy fruit production; S3 = low fleshy fruit but high acorn production

\begin{tabular}{|c|c|c|c|c|c|c|c|c|c|}
\hline \multirow[b]{2}{*}{ Site } & \multicolumn{3}{|c|}{ Time to encounter the stations (d) } & \multicolumn{3}{|c|}{ Initial removal rate (\%) } & \multicolumn{3}{|c|}{ Fruits opened to extract the seeds (\%) } \\
\hline & $(\bar{x} \pm \mathrm{SE})$ & $t$ value & $P$ value & $(\bar{x} \pm \mathrm{SE})$ & $Z$ value & $P$ value & $(\bar{x} \pm \mathrm{SE})$ & $Z$ value & $P$ value \\
\hline S1 & $4.6 \pm 3.4$ & $\mathrm{~S} 1-\mathrm{S} 2: \mathbf{1 7 . 1 1}$ & $<0.001$ & $4.9 \pm 3.6$ & $\mathrm{~S} 1-\mathrm{S} 2:-4.61$ & $<0.001$ & $87.6 \pm 24.5$ & $\mathrm{~S} 1-\mathrm{S} 2: \mathbf{2 . 1 1}$ & 0.035 \\
\hline S2 & $1.3 \pm 0.7$ & S2-S3: 14.10 & $<0.001$ & $32.3 \pm 20.1$ & S2-S3: -4.02 & $<0.001$ & $66.1 \pm 21.8$ & S2-S3: 0.39 & 0.694 \\
\hline S3 & $3.9 \pm 2.7$ & S3-S1: 2.49 & 0.013 & $7.1 \pm 6.8$ & S3-S1: -0.84 & 0.401 & $80.9 \pm 22.4$ & S3-S1: 0.31 & 0.757 \\
\hline
\end{tabular}

Bold type indicates statistical significance.

We found that rodents remove seeds from all the fleshy-fruited species studied, although some of them have been said to be dispersed/predated only by birds and large mammals, as in the case of $S$. aucuparia (Raspé et al., 2000). Other studies also found high rates of seed removal by rodents in fleshy-fruited species such as I. aquifolium (Obeso and Fernández-Calvo, 2002). We found that seed fate was affected by the presentation of the seed (inside the fruit versus cleaned). Rodents removed the cleaned seeds from the ground more rapidly, clearly preferring seeds to fruits, which supports our first prediction. Seeds contain proportionally more lipids than fruits and, thus, higher energy content for rodents, in agreement with other nutrition and foraging studies (Vander Wall, 1990; Kerley and Erasmus, 1991). However, seed size did not appear to be a key factor among fleshyfruited species. Crataegus had the largest seed size and the lowest removal rate, indicating that intrinsic characteristics, such as chemical or physical properties, are more important factors. Kollmann et al. (1998) found that seeds with high woody endocarps (fibrous coat) are less preferred. We obtained three significant groups of seed preference: Sorbus and Ilex as favourite seeds with no differences among species, followed by $R$. canina and finally $C$. monogyna with the lowest removal rate. C. monogyna and $R$. canina seeds contained as fibrous coat more than $90 \%$ and $80 \%$ of the seed mass, respectively (Kollmann et al., 1998). Moreover, the smallest seeds were the best preferred (S. aucuparia), probably due to their high content in proteins and fat $(42 \%$ of the dry matter; Pulliainen, 1978). Thus, seed size seems not to be a key factor compared to physical and chemical properties and, thus, our second prediction about preference for larger seeds was not supported. Regarding fruit selection, pomes from Sorbus sp. had the highest removal rates. However, no differences were found in removal rates of fruits though fruit size differences are noticeable (Table 3). Herrera (1987) in a general study of fruit characteristics found small differences in the pulp constitutes of the five species studied. Again, chemical properties seem to exceed the importance of fruit size in fruit removal by rodents.
Although seeds from the fruits were removed more slowly than seeds on the ground, seed extraction from the fruit was found in a high proportion $(78.2 \%$ of the non-intact fruits). Most of the fruit pulp was incompletely consumed by rodents. However, seeds were extracted from the fruits, revealing a preference for the seeds. Some of the fruits only showed small bites to reach the seeds, leaving the fruit pulp almost intact. This behaviour is probably due to the higher cost (in time and energy) of handling and opening the fruits, which eventually entail not only lower energy intake but also higher predation risk (Fedriani and Manzaneda, 2005). Although sites may differ in other characteristics besides food availability and rodent density, it seems that seed extraction from the pulp depends on seed availability, which strongly differed among sites. Thus, when fleshy fruit density is higher, more seeds are extracted from the fruits, resulting in significant differences compared to the site with low fruit density (Table 4). We suggest that this is probably due to the lack of food, since a high amount of alternative food (nuts) but low fruit density caused no differences in seed extraction compared to high fruit density (Table 4). Consequently, high food availability (either alternative food or fleshy fruits) probably makes rodents change their removal rates of seeds from the pulp of the fleshy fruits. Rodents with high food availability will only remove the most valuable food (seeds) and at low removal rates, avoiding lowervalue food (pulp). This supports the suggestion that changes in foraging costs due to the presentation of higher-value food have an important impact on the fate of low-value seeds (e.g. removed or not), in agreement with Fedriani and Manzaneda (2005). In addition, rodents encounter the stations more rapidly in the site with low food availability and first removed the higher-value food (seeds), even from the inside of the fruits. Although these findings partially support our last two predictions, more specific studies (controlling for all possible confounding factors) with a higher number of replicates are needed. Besides, time should be considered in removal studies since at the end of the seed offer ( 1 month) we found no significant differences among sites (Table 2), revealing that seed 
removal differences become shorter as a consequence of a gradual food depletion.

Estimations of rodent population significantly decreased throughout autumn when food availability was low. Nonetheless, removal rates under low rodent abundance were the highest. Probably, shortage of food makes rodents forage in a wider area, finding the stations more easily and causing higher removal rates (Table 4). This agrees with the fact that territory size is inversely related to food availability (Jones, 1990). Thus, lower rodent densities did not result in lower removal rates, as has been suggested in other studies (Hulme and Borelli, 1999), contradicting the second part of our last prediction. Hulme (1994) argued that the main determinant of removal rates within a habitat was the spatial distribution of rodents in preferred microhabitats. Perea et al. (2011) also found that seeds located under shrub cover were first encountered and removed in comparison to other microhabitats, resulting in the main encounter factor. In this study we used the preferred microhabitat (shrub) for the location of all stations, to avoid possible differences in the spatial distribution of seed removal. Surprisingly, we obtained a slower encounter rate in the highest rodent density which contained more food (nuts). This supports the possibility that food availability and its quality are important factors in determining seed and fruit removal in fleshy fruits and that higher rodent abundance is not necessarily associated with higher removal rates. However, these findings would need larger manipulative studies to better discriminate between rodent density and food availability.

After 1 month of seed and fruit offer, most of the fruits and seeds were encountered and taken. Nevertheless, removal rates were very different throughout autumn, especially in the beginning (initial fate). Delay in seed and fruit removal may be a determining factor in seed viability. In this study, seeds and fruits that were not removed, or were removed later, showed biotic damage (fungi). Although rodents may consume a great amount of fruits and seeds, they also store seeds to overwinter by burying them under the ground or within the litter (Den Ouden et al., 2005; Gómez et al., 2008; Perea et al., 2011), avoiding biotic damage (Lambert, 2002). In addition, scatter-hoarding rodents, such as wood mice, enhance the redistribution of nuts and avoid seedling competition (Perea et al., 2011). Birds drop their faeces on the ground surface containing, very often, several seeds together, whereas scatter-hoarding rodents move the seeds to the soil or litter environment, increasing the probability of seed viability and successful recruitment (Vander Wall et al., 2005). However, this study did not address seed dispersal from fleshy-fruited species, which could help us to elucidate the real consequences of seed removal by rodents. Thus, further studies are needed to assess the balance between seed predation and effective seed dispersal through rodents, because important differences may exist between the dispersal of nuts and the possible dispersal of lower-value items such as fleshy fruits. Despite this, seeds from fruits usually germinate more readily if the pulp is cleaned away, with no differences in germination compared to seeds regurgitated or defecated by birds (Barnea et al., 1991; Yagihashi et al., 1998). In that way, rodents might enhance seed germination by extracting the seeds from the fruits, as has been observed in this study.

Since all seeds and fruits are eventually located on the ground and mostly removed by rodents, the effectiveness of rodents as dispersers of fleshy-fruited species deserves further attention. This study only underlines that scatter-hoarding rodents are important removers of fleshy fruits and their seeds, producing a differential seed removal depending on the seed presentation (with or without pulp), the nutritional properties of the seeds (but not of the fruits) and the presence of alternative food. Rodent abundance, fruit and seed size seem to be minor factors on the removal of fleshy fruits and their seeds.

\section{Acknowledgements}

We thank Jesús Alonso and Rocío González for their assistance in the field and M. Fernández-Olalla and M. Martínez-Jauregui for valuable comments on data analysis. Ramón Perea is supported by a $\mathrm{PhD}$ grant from the Universidad Politécnica de Madrid. This study was funded by the Comunidad Autónoma de Madrid and project AGL2006-00813 of the Spanish Comisión Interministerial de Ciencia y Tecnología (CICYT).

\section{References}

Barnea, A., Yom-Tov, Y. and Friedman, J. (1991) Does ingestion by birds affect seed germination? Functional Ecology 5, 394-402.

Brown, J.S. and Kotler, B.P. (2004) Hazardous duty pay and the foraging cost of predation. Ecology Letters 7, 999-1014.

Crawley, M.J. (2007) The R book. England, Wiley Editorial.

Den Ouden, J., Jansen, P.A. and Smit, R. (2005) Jays, mice and oaks: Predation and dispersal of Quercus robur and Q. petraea in north-western Europe. pp. 223-240 in Forget, P.M.; Lambert, J.; Vander Wall, S.B. (Eds) Seed fate. Wallingford, UK, CABI Publishing.

Fedriani, J.M. and Manzaneda, A.J. (2005) Pre- and postdispersal seed predation by rodents; balance of food and safety. Behavioral Ecology 16, 1018-1024.

García, A. (2006) Dinámica forestal del Hayedo de Montejo en la última década mediante comparación de dos inventarios sucesivos. EUIT Forestal. Universidad Politécnica de Madrid, Madrid.

Gómez, J.M., Puerta-Piñero, C. and Schupp, E.W. (2008) Effectiveness of rodents as local seed dispersers of Holm oaks. Oecologia 155, 529-537. 
Herrera, C.M. (1984) A study of avian frugivores, birddispersed plants, and their interaction in Mediterranean scrublands. Ecological Monographs 54, 1-23.

Herrera, C.M. (1987) Vertebrate-dispersed plants of the Iberian Peninsula: a study of fruit characteristics. Ecological Monographs 57, 305-331.

Herrera, C.M. (1989) Frugivory and seed dispersal by carnivorous mammals, and associated fruit characteristics, in undisturbed Mediterranean habitats. Oikos 55, $250-262$.

Howe, H.F. (1989) Scatter- and clump-dispersal and seedling demography: hypothesis and implications. Oecologia 79, 417-426.

Hulme, P.E. (1994) Rodent post-dispersal seed predation in grassland: magnitude and sources of variation. Journal of Ecology 82, 645-652.

Hulme, P.E. (1998) Post-dispersal seed predation: consequences for plant demography and evolution. Perspectives in Plant Ecology, Evolution and Systematics 1, 32-46.

Hulme, P.E. and Borelli, T. (1999) Variability in postdispersal seed predation in deciduous woodland: relative importance of location, seed species, burial and density. Plant Ecology 145, 149-156.

Janzen, D.H. (1971) Seed predation by animals. Annual Review of Ecology and Systematics 2, 465-492.

Jones, E. (1990) Effects of forage availability on home range and population density of Microtus pennsylvanicus. Journal of Mammalogy 71, 382-389.

Kerley, G.I.H. and Erasmus, T. (1991) What do mice select for in seeds? Oecologia 86, 261-267.

Kollmann, J., Coomes, D.A. and White, S.M. (1998) Consistencies in post-dispersal seed predation of temperate fleshy-fruited species among seasons, years and sites. Functional Ecology 12, 683-690.

Krebs, C.J. (1999) Ecological methodology (2nd edition). New York, Addison-Wesley.

Lambert, J.E. (2002) Exploring the link between animal frugivory and plant strategies: the case of primate fruitprocessing and post-dispersal seed fate. pp. 365-379 in Levey, D.J.; Silva, W.R.; Galetti, M. (Eds) Seed dispersal and frugivory: Ecology, evolution and conservation. Wallingford, UK, CAB International.

Obeso, J.R. and Fernández-Calvo, I. (2002) Fruit removal, pyrene dispersal, post-dispersal predation and seedling establishment of a bird-dispersed tree. Plant Ecology 165, 223-233.
Pardo, F., Gil, L. and Pardos, J.A. (2004) Structure and composition of pole-stage stands developed in an ancient wood pasture in central Spain. Forestry 77, 67-74.

Perea, R., San Miguel, A. and Gil, L. (2011) Leftovers in seed dispersal: ecological implications of partial seed consumption for oak regeneration. Journal of Ecology 99, 194-201.

Puerta-Piñero, C., Gómez, J.M. and Schupp, E.W. (2010) Spatial patterns of acorn dispersal by rodents: do acorn crop size and ungulate presence matter? Oikos 119, $179-187$.

Pulliainen, E. (1978) The nutritive value of rowan-berries, Sorbus aucuparia L., for birds and mammals. Aquilo, Serie Zoologica 18, 28-32.

Raspé, O., Findlay, C. and Jacquemart, L. (2000) Sorbus aucuparia L. Journal of Ecology 88, 910-930.

Schupp, E.W. (1988) Seed and early seedling predation in the forest understory and in the tree fall gaps. Oikos 51, 71-78.

Stephens, D.W. and Krebs, J.R. (1986) Foraging theory. Monographs in behaviour and ecology. Princeton, USA, Princeton University Press.

Valbuena-Carabaña, M., González-Martínez, S.C., Sork, V.L., Collada, C., Soto, A., Goicoechea, P.G. and Gil, L. (2005) Gene flow and hybridisation in a mixed oak forest (Quercus pyrenaica Willd. and Quercus petraea (Matts.) Liebl.) in central Spain. Heredity 95, 457-465.

Vander Wall, S.B. (1990) Food hoarding in animals. Chicago, USA, University of Chicago Press.

Vander Wall, S.B. (2001) The evolutionary ecology of nut dispersal. Botanical Review 67, 74-117.

Vander Wall, S.B. (2003) Effects of seed size of winddispersed pines (Pinus) on secondary seed dispersal and the caching behavior of rodents. Oikos 100, 25-34.

Vander Wall, S.B., Kuhn, K. and Gworek, J. (2005) Twophase seed dispersal: linking the effects of frugivorous birds and seed-caching rodents. Oecologia 145, 282-287.

Wang, B. and Chen, J. (2008) An experiment using artificial 'seeds'. Acta Oecologica 34, 379-385.

Willson, M.F. (1993) Mammals as seed-dispersal mutualists in North America. Oikos 67, 159-176.

Xiao, Z.S., Zhang, Z.B. and Whang, Y.S. (2005) Effects of seed size on dispersal distance in five rodent-dispersed fagaceous species. Acta Oecologica 28, 221-229.

Yagihashi, T., Hayashida, M. and Miyamoto, T. (1998) Effects of bird ingestion on seed germination of Sorbus commixta. Oecologia 114, 209-212. 